\title{
A Synthesis of Pedagogical Factors for the Future of Fashion Design Curricula
}

\author{
Brooke Brandewie, University of Cincinnati, USA \\ Injoo Kim, University of Cincinnati, USA
}

Keywords: fashion design, pedagogy, Generation Z, higher education

\section{Background}

As educators we are consistently evolving new curricula for the next generation. Interestingly this pandemic situation has required us to teach remotely, which at first, was alarming given the studio-oriented, hands-on nature that characterizes design education. This study has demonstrated that students can adjust readily to online remote learning, and just after one month into it, we have witnessed first-hand how quickly they learn and adapt. Renfro (2015) points out that this younger generation has less need for direction because they have access to all of the answers, especially for things they are passionate about. They care about practicing sustainability, with great concern for our collective wellbeing. These students are indeed adaptable and have a creative, open mindset. The unique confluence of circumstances - a tough economy, increasingly competitive college market, expanding networks and shifts in technology - is creating a culture of innovators (Johnson, 2015).

Given these qualities and the times we are in, we must carefully continue to consider how to revamp curricula, and what our role in design education needs to be into the future. This paper provides an overarching synthesis of findings from our pedagogical research efforts towards the collective conversation on the future of fashion design higher education.

\section{Problem Statement}

Reflective of the qualities of Gen Z, the Maker movement is a societal trend that has increased in prevalence over the past two decades. It is a movement (much like what is being accentuated today) that embodies meaning and authenticity, slowing down, simplifying, and streamlining. It is oriented to be collective, valuing people, place and process, whether it is embracing communal engagement, or supporting exclusive, artisanal hand-crafted goods. As we have witnessed, there has been a great decline in big box stores and corporations. Fast-fashion and mass production has given way to small-batch entrepreneurship and personalization. As of 
2015, small businesses employed 58.9 million people in the U.S, or about $47.5 \%$ of the total private sector workforce, demonstrating how crucial they are to the economy (USSBA, 2018). Owning the trendiest fashions for self-promotion is now replaced by the desire for quality, meaningful exchanges and experiences. This sentiment was echoed by Li Edelkoort in her AntiFashion Manifesto (2015) stating, "the consumers of today and tomorrow are going to choose for themselves, creating and designing their own wardrobes; sharing clothes amongst each other since ownership doesn't mean a thing anymore". This pandemic will only accentuate the values of Maker culture, as it represents a decentralized platform that allows everybody to tackle the same issue, communally \& locally, and furthermore serves as evidence that digital collaborative efforts will drive future impact (Singh \& Singh, 2020).

\section{Approach / Methodology}

Research activities included 1) online surveys with over 65 industry professional design alumni, as well as 2) a workshop with 34 faculty educators, to explore how higher education should evolve. Faculty aimed to gauge active industry professionals' perspectives through the survey. The survey contained a total of 8 questions, focusing on what skills the participants learned from education and industry that they felt were most important, along with what they believed to be essential in curriculum development.

The International Textiles and Apparel Association (ITAA) is an organization that highly represents scholarly work, consisting of a group of international faculty with vetted interests in fashion design pedagogy. Faculty wanted to leverage the ITAA Conference as a means for the scholars to explore the current and future trajectory of fashion design curricula through a series of curated activities. The workshop was designed as an interactive session in four phases. There were 6 groups with 5-6 people in each group. Each activity was planned to encourage individual input, followed by group discussion and synthesis of ideas. Then each group shared out the takeaways from each activity. Lastly student interviews, in addition to literature reviews were conducted to corroborate findings from these research activities.

\section{Findings \& Analysis}

From the survey, we learned that participants felt that "Technology/Software, Critical Thinking/Problem solving (Research)", as well as "Textiles/Fabric Development (I.e. screen printing, fabric printing, surface/fabric manipulation)" were the most important areas to develop skills in through higher education. Furthermore, the top skills alumni used the most in their professional work were, "Critical Thinking/Problem solving", "Technical skills (both CAD/software and hands-on design development)", and "Research Methods". 
In the workshop, the educator participants acknowledged that "Entrepreneurship" and "Branding" was important. Not surprisingly, "Sustainability" alongside of "Having a greater understanding of systems" and "Product Development (ethical sourcing, circularity, life cycle analysis, etc.)" were highlighted by all groups. "Critical thinking/Problem solving and Research" were also underscored. These findings are indicative that the industry (and students graduating out of higher education programs) need to evolve to be more responsible and thoughtful in the design development process, without disregard to the importance of quality and creativity.

"Soft skills" were frequently mentioned, including characteristics such as "Flexibility, adaptability and responsibility", as well as "professionalism", "communication" and "having a growth mindset". These findings suggest that higher education should prioritize soft skills within curriculum development, and value teaching these skills just as they do hard skills.

The workshop findings reflected similar takeaways from the survey, which also are in-line with our own observations working with these students over the past several years. These students are motivating us to teach them the skills and tools to be responsible, sustainable contributors to society. They are more quality-driven, desiring to support and develop smallbatch self-made brands that thrive on a sense of community and accountability. They value the tactility and hands-on nature of design process along with face-to-face interaction, and this further encourages design creativity. Therefore, technology and online tools will extend students' potential and equip them to work more efficiently and effectively.

\section{Conclusion}

This paper reflects pedagogical research efforts by synthesizing overarching findings from both industry and academic perspectives for fashion design curricula. Overall, the educator's role into the future will be as an orchestrator of online and offline design education, adopting interchangeable, flexible and interactive approaches to learning.

A nimble and rapid innovation process is central to the Maker movement, which aligns with the entrepreneurial and innovative nature of this younger generation. Emphasis on critical thinking, research and problem solving is deeply important, since this cohort of students consider sustainability a crucial priority, giving more weight to innovating the supply chain, sourcing and best practices for how product is realized from conception to end of its life, and thereafter. Understanding the 'why' and 'how' behind decision making in order to be more considerate and accountable is also crucial. This new cohort of learners prefers not to be labeled, expects flexibility, and prefers customization (Renfro, 2015). Therefore, adjusting our teaching approaches and curriculum offerings to allow for specialization is highly desirable.

Page 3 of 4

(c) 2020 The author(s). Published under a Creative Commons Attribution License (https://creativecommons.org/licenses/by/4.0/), which permits unrestricted use, distribution, and reproduction in any medium, provided the original work is properly cited.

ITAA Proceedings, \#77 - https://itaaonline.org 


\section{References:}

Edelkoort, L. (2015). ANTI_FASHION, a manifesto for the next decade. Trend Union. pp 1-8.

Johnson, W. (2015, May 15). Why Today's Teens are More Entrepreneurial Than Their Parents. Retrieved April 8, 2020, from https://hbr.org/2015/05/why-todays-teens-are-moreentrepreneurial-than-their-parents

Renfro, A. (2012, December 5). Meet Generation Z. Getting Smart. Retrieved from http://gettingsmart.com/2012/12/meet-generation-z/

Singh, G., \& Singh, R. P. (2020, April 14). Future of the Maker Movement is Here, Catalyzed by COVID-19. Retrieved April 14, 2020, from https://www.digitalnewsasia.com/insights/futuremaker-movement-here-catalysed-covid-19

U.S Small Business Administration, Office of Advocacy. (2018). Retrieved April 5, 2020, from https://www.sba.gov/sites/default/files/advocacy/2018-Small-Business-Profiles-US.pdf 